\title{
COVID-19 outbreak lockdown and its impacts on marketing of horticultural produces in Zimbabwe
}

\author{
Parwada, C. \\ Women's University in Africa, Department of Horticulture, Marondera, Zimbabwe \\ Author for correspondence: cparwada@gmail.com
}

\begin{abstract}
Summary: Coronavirus disease of 2019 (COVID-2019) outbreak resulted to a global health problem. Lockdown was one of the common options suggested to curb the pandemic. Horticultural produces are perishable so delayed post-harvest marketing cause losses. This study aimed at evaluating the marketing of horticultural produces and farmers' level of preparedness during the COVID-19 lockdown. A self-administered questionnaire was posted online from April 7 to May 7, 2020 the first month of COVID-19 lockdown in Zimbabwe (began on March 30, 2020). The study targeted horticultural farmers around Harare peri-urban and had 300 respondents. Data on sociodemographic, farmers' behavior, awareness and attitude toward marketing and desire to minimize post-harvest losses was obtained. Frequency counts and percentages were determined. Chi-square tests on independent variables were done to test associations with demographics using SPSS version 8 . There were significant $(\mathrm{P}<0.05)$ relations between awareness and attitude toward marketing, age and level of education. Demographic variable influenced the famers' marketing behavior and attitude during COVID-19 lockdown. Most farmers reported highest (>35\%) produce sale leftovers at the markets and spoilage during than prior the COVID-19 lockdown. The lockdown resulted to low sales and most farmers were unprepared for any crisis during the marketing stage of their production. The research contributed to an understanding of how a crisis situation influence marketing of horticultural produce and raises awareness regarding post-harvest losses. A qualitative study is recommended as a follow-up of this work.
\end{abstract}

Parwada, C. (2020): COVID-19 outbreak lockdown and its impacts on marketing of horticultural produces in Zimbabwe. International Journal of Horticultural Science 26: 38-45. https://doi.org/10.31421/IJHS/26/2020/6178

Key words: demand, horticulture, market accessibility, marketing, perishable, post-harvest losses

\section{Introduction}

The start of 2020 coincided with the outbreak of coronavirus disease of 2019 (COVID-19) (WHO, 2020). The causative virus of COVID-19 can easily and sustainably spread by contact from person to person. The disease is characterized by respiratory illness and death of people especially the aged and those with medical conditions (CDC, 2020). In $<3$ months from the first confirmed (December 2019) COVID-19 case in Wuhan, China, the virus swept across the world at a furious space. The virus has infected $>1.3$ million people worldwide as by 30 April 2020, with > 83500 deaths (WHO, 2020) and Zimbabwe has not been spared by the devastating disease. There is no specific vaccines or treatment for the COVID-19, most countries including Zimbabwe called for total national lockdown as a strategy to limit the spread of the virus. The lockdown was aimed at controlling spread of the virus by social distancing people, shutting down of schools, colleges and universities and avoiding non-essential activities (CDC, 2020). Records showed that as of December 2019 to March 2020 , more than one third of the world population was under COVID-19 lockdown (WHO, 2020). During the lockdown period, governments urged their people to stay home and move only when accessing the essentials like food.

The Zimbabwean government declared the COVID-19 total national lockdown as from the $30^{\text {th }}$ of March 2020, announced emergency regulations and delegated personnel to combat the disease (https://www.voanews.com>zimbabwe). Zimbabwe started its lockdown with a 21-day nationwide shutdown and was further extended until 16-May 2020 before an indefinite extension as of May 16, 2020 till further notice. Many horticultural farmers had some of their produce ready for the marketing by the time of the COVID-19 lockdown pronouncement where some crops matured during the lockdown period. The restriction of movements slowed the delivery of produce to the farmer markets and limited market accessibility to both the farmers and customers. Consequences of restricted movement of people could lead to the accumulation of produce stock at the farm and reduced sales due to few customers. This resulted to a sudden increase in need for the post-harvest handling requirements at the farms. Creating a challenge where farmers lose their produce due to spoilage especially when no or poor-post harvest handling facilities existed.

Zimbabwe has an agro-based economy and many households rely on farming. Horticulture production is one of the main farming activity for food in both urban and rural Zimbabwe. Horticultural producers earn higher farm income in comparison to cereal producers with five times higher per capital farm income (Zimbabwe Horticulture Promotion Council, 2013). In addition, horticultural products are considered to be incomeboosting alternatives to basic grains for smallholder farmers, and have contributed to employment opportunities (World Bank, 2008). In Zimbabwe, crops like tomatoes and onions are consumed in almost all the three daily meals e.g are eaten either raw or cooked during breakfasts, lunches and suppers. Therefore, the crops have a higher daily demand compared to nonhorticultural crops such as maize, sorghum hence are produced oftentimes. However, the horticultural crops are highly perishable so reliable markets are an essential if commercially produced. A delay in marketing after harvesting will result to a 
rapid loss of saleable quality and quantity. If farmers produce more than what the available market can absorb, there are increased chances of post-harvest losses especially if there are poor or no post-harvest handling facilities. Therefore, commercial production levels of horticultural crops has to be balanced with the available markets.

Marketing of horticultural products is dynamic so limited knowledge about the markets will result to huge losses. Regrettably, in Zimbabwe, quantities of horticulture produce losses from spoilage (15\%) and market glut (60\%) are significant especially during the peak production periods (Zimbabwe Horticulture Promotion Council, 2013). The produce losses are caused also by the limited access to higher value urban markets by the smallholder horticulture producers. The sudden outbreak of COVID-19 led to an unexpected severe imbalance between the production levels and market availability.

Zimbabwe Horticulture Promotion Council (2013) condemned that many smallholder horticultural farmers lack established and well equipped post-harvest storage facilities leading to huge produce losses. The COVID-19 lockdown restricted people movement to places outside their homes hence the horticultural markets were partially inaccessible to both the farmers and consumers. The movement and physical distancing restrictions could widened the contact gap between the farmers and their customers and caused an unplanned high volume of produce stocks at farms. Cases of produce sale leftovers were likely to increase during the lockdown period. Prior to the COVID-19 lockdown, farmers were easily accessing the markets and achieved high sales per day with little or no leftovers. The farmers were likely to incur huge financial losses as a result of the sudden increase in storage demands. Considering that the horticultural produce are fresh and highly perishable by nature, the smallholder farmers with limited post-harvest handling facilities are obvious faced with storage challenge. The impact of the COVID-19 lockdown on horticultural marketing has not been studied.

In Zimbabwe, the smallholder horticulture farmers use the informal markets mostly when selling their crop produce. The produce is delivered directly to farmer markets, sold to the middlemen (usually selling at farm-gate) or directly to the final customer. Prices in the horticultural industry are not regulated and are usually determined by the prevailing demand. Modern marketing methods such as the online and e-commerce are not commonly used in the Zimbabwean horticultural industry. Hence physical movement from the farm to the markets is involved somehow in any way of marketing. Therefore there was an anticipated drop in horticultural produce sales as a result of limited access to the markets due to the COVID-19 lockdown. This marketing dilemma for the horticulture produce was worth studying so that both tactical and strategic solutions are developed. The impact of COVID-19 lockdown on the post-harvest losses were determined by evaluating market availability for the produce. In this study, it was assumed that most smallholder horticultural farmers had not planned for the unexpected additional requirement of postharvest handling facilities for their produce. Market availability had therefore influence the farmers' crop production quantities. The specific objectives of the current work were to evaluate the impact of COVID-19 lockdown on post-harvest losses of horticultural crops and assessing horticultural farmers' preparedness to eventualities such as the COVID-19 outbreak.

\section{Materials and methods}

An online survey was done using a self-administered structured questionnaire on horticultural farmers around Harare peri-urban, Zimbabwe. The questionnaire was developed and administered in English from April 7 until May 7, 2020, during the first month of COVID-19 outbreak lockdown (begins on March 30, 2020 in Zimbabwe), through the social media (https://www.facebook.com/) and by mailing. The study period consisted of 14 days of the first 21 days (30 March-20 April 2020) of total shutdown where movement outside homes was prohibited and another 14 days in the level 2 (restricted movements and protective requirements) of the COVID-19 lockdown. The respondents were selected on a voluntary basis and the sample size was approximated according to the sphere of influence of the horticultural markets.

The questionnaire had 25 one option and multiple choice questions grouped into 6 sections: (1) main horticultural crops produced (2) socio-demographic characteristics of the respondents (gender, age, education and household size); (3) awareness and attitude toward horticultural markets; (4) horticultural production and marketing behaviors and attitudes; (5) quantity of horticultural produce sold and (6) information needs and willingness to reduce produce losses.

\section{Data analysis}

The data was analyzed by frequency counts and percentages using Microsoft Excel software. Chi-square tests on the independence of variables were also done to test for the associations with demographic variables using SPSS version 8 . The statistical significance was determined at $\mathrm{p}<0.05$.

\section{Results and discussion}

\section{Sociodemographics of the respondents}

The demographics (Table 1) showed that $61 \%$ of the respondents were women, $56 \%$ were households with $>4$ members, $72 \%$ were dependent on farming (horticulture) and $59 \%$ had tertiary (level 2) education. This could be caused by the voluntary recruitment of respondents, the social media mode of administration and as well as the language used (English). The sampling design was non-probabilistic and representative of the peri-urban horticultural farmers in Zimbabwe. The sampling design is similar to a study by Sassi et al. (2016), in terms of gender and education.

The online surveys were financially cheap, simple to carry out and did not require a physical contact between the interviewers and the respondents as this was the concern during COVID-19 outbreak lockdown. The design provided a large view of horticulture produce markets-related issues. Nevertheless, the online surveys could not reach people that were technophobia or unable to access the technology (no data bundles), such low income, poorly educated persons or elderly. Moreover, the online survey may not allow an in-depth analysis of the results.

The respondents indicated that ten horticultural crops were ready for market during the COVID-19 lockdown period (April 7 to May 7, 2020). Leaf vegetables and butternuts were the most (32\%) and least (2\%) common crops respectively (Table 2). About 5\% respondents indicated other crops (Table 2). 
Table 1. Respondent profiles.

\begin{tabular}{|c|c|}
\hline & $\%$ of respondents \\
\hline \multicolumn{2}{|l|}{ Gender } \\
\hline Women & 61 \\
\hline Men & 39 \\
\hline \multicolumn{2}{|l|}{ Age (years old) } \\
\hline $18-30$ & 16 \\
\hline $31-40$ & 28 \\
\hline $41-60$ & 34 \\
\hline$>61$ & 22 \\
\hline \multicolumn{2}{|c|}{ Number of persons in the household } \\
\hline 1 & 4 \\
\hline 2 & 10 \\
\hline 3 & 30 \\
\hline$>4$ & 56 \\
\hline \multicolumn{2}{|l|}{ Education* } \\
\hline Level 0 & 3 \\
\hline Level 1 & 38 \\
\hline Level 2 & 59 \\
\hline \multicolumn{2}{|l|}{ Main sources of income } \\
\hline Farming (horticulture) & 72 \\
\hline Employment other farming & 17 \\
\hline Other sources & 11 \\
\hline
\end{tabular}

Table 2. Results* of the horticultural crops that were ready for the market as from April 7 to May 7, 2020 during the lockdown period $(n=300)$.

\begin{tabular}{lc}
\hline Horticultural Crop & \% respondents \\
\hline Leaf vegetables & $32^{*}$ \\
Tomatoes & 29 \\
Potatoes & 8 \\
Green beans & 5 \\
Cucumber & 4 \\
Avocado & 3 \\
Sweet potatoes & 4 \\
Onion & 5 \\
Okra & 3 \\
Butternuts & 2 \\
Others & 5
\end{tabular}

*Percentage of the respondents

Many farmers were into leaf vegetable and tomato production and very few produced butternuts. The differences in crop production could be due to the frequent use of the crops. Leaf vegetables and tomatoes are eaten in many meals e.g are eaten either cooked or raw during breakfasts, lunches and suppers. Therefore, this high consumption rate is likely increase their demand at the market and this may explain the high number of farmers were producing the leaf vegetables and tomatoes. Time of the year (growing season) could have influenced the noted differences in crop production. Crops like the sweet potatoes and onion are biannual so they were offseason during the study period.

At least $63 \%$ of the respondents indicated $<15 \%$ produce sale leftovers at the markets on the ten crops prior than during to the COVID-19 lockdown. Only $48 \%$ indicated $<15 \%$ produce sale leftover at the markets (Table 3). Whilst at least $79 \%$ of the farmers indicated $<35 \%$ produce sale leftover during the COVID-19 lockdown (Table 3).

The percentage of respondents who indicated produce sale leftover of $<15 \%$ and $16-20 \%$ at the market were higher prior than during the COVID-19 lockdown (Table 3). However, the respondents who indicated percentage sale leftovers of $21-35 \%$ and $>35 \%$ were higher during than prior the COVID-19 lockdown on all the crops. This results confirm the negative impact of the COVID-19 lockdown on the marketing of horticultural produce. Prior COVID-19 lockdown, the farmers and customer could easily access the markets hence high sales and less leftovers. However, during the COVID-19 lockdown, the movement restrictions limited market accessibility resulting to high $(>35 \%)$ sales leftovers.

\section{Awareness and attitude toward marketing of horticultural produce during the lockdown}

Loss of horticultural produce can be attributed to the relationship between the level of production (quantity produced) and market availability, it was important to estimate producer awareness, especially in crisis situations e.g COVID19 outbreak (Table 4). Significantly $(\mathrm{P}<0.05)$ positive relations were obtained between awareness, age and education. These results agree with Qi and Roe (2016) who have reported similar significant associations between agricultural production knowledge and demographics like age and employment status. Interestingly, $78 \%$ of the respondents had not planned for any unusual marketing time like the restricted access of markets during the COVID-19 lockdown, whereas only $8 \%$ indicated that they were prepared for any market eventualities e.g COVID-19 lockdown on their production levels (Table 4). Age and education significantly $(\mathrm{P}<0.05)$ influenced the efforts to limit produce losses during COVID-19 lockdown. The results also showed a significant relation between reported efforts to limit produce losses and the number of members per household. In this study, it was necessary to note that the horticulture was the main source of income and consequently any loss of produce would directly cause reduced income. United Nation (2009) have shown that post-harvest losses were positively correlated with market availability especially when the farmers have poor post-harvest handling facilities. In most countries, the announcement of lockdown was sudden and farmers could not plan on the quantities to produce neither on how to minimize losses as a result of restricted markets accessibility.

About $8 \%$ of the respondents indicated that they had strategies to minimize losses of their produce well in place before the COVID-19 lockdown. Table 2 indicates significant associations between production behaviors and demographics (gender, age, household occupants and education). Women, persons more than $>61$ years old and tertiary-educated people tend to reduce produce loss by reducing selling prices towards markets closure, whereas as men and less educated people carry the unsold produce back home.

All $(100 \%)$ of respondents indicated that they were worried about produce losses and wanted to avoid it by any means possible. The findings are similar to those of Fanelli \& Di Florio (2016), who showed increased levels of awareness and changes in attitudes, toward agricultural produce losses during times of crisis. This high level of awareness about the produce losses constitute an important condition for a future behavior change of the horticultural farmers.

On the question "Has COVID-19 lockdown altered your management practices of the unsold produce at the close of markets?" $82 \%$ of respondents have answered to suddenly reduce prices in a way to attract customers, 5\% take the produce back home and $13 \%$ indicated processing (value addition) of the sales leftovers (Table 4). Gender, age, number of members per household and education significantly affects the management practices of unsold produce at the close of markets (Table 4). 
Table 3. Results* for the horticultural produce sales leftover at the markets prior and during the lockdown $(\mathrm{n}=300)$

\begin{tabular}{|c|c|c|c|c|c|c|c|c|}
\hline \multirow[b]{2}{*}{$\%$ sale leftover } & Prior & During & Prior & During & Prior & During & Prior & During \\
\hline & \multicolumn{2}{|c|}{$<15 \%$} & \multicolumn{2}{|c|}{$16-20 \%$} & \multicolumn{2}{|c|}{$21-35 \%$} & \multicolumn{2}{|c|}{$>35 \%$} \\
\hline Leaf vegetables & $92 *$ & 8 & 70 & 30 & 19 & 81 & 5 & 95 \\
\hline Tomatoes & 80 & 10 & 68 & 32 & 18 & 82 & 6 & 94 \\
\hline Potatoes & 76 & 24 & 64 & 36 & 26 & 74 & 14 & 86 \\
\hline Sweet potatoes & 72 & 28 & 66 & 34 & 30 & 70 & 16 & 84 \\
\hline Avocado & 63 & 37 & 59 & 41 & 35 & 65 & 17 & 83 \\
\hline Green beans & 75 & 25 & 65 & 35 & 26 & 74 & 18 & 82 \\
\hline Onions & 82 & 18 & 76 & 24 & 30 & 70 & 13 & 87 \\
\hline Cucumber & 77 & 23 & 70 & 30 & 28 & 82 & 11 & 89 \\
\hline Butternuts & 68 & 32 & 63 & 37 & 33 & 67 & 18 & 82 \\
\hline Okra & 69 & 31 & 60 & 40 & 29 & 71 & 20 & 80 \\
\hline Others & 48 & 52 & 45 & 55 & 33 & 67 & 21 & 79 \\
\hline
\end{tabular}

*Percentage of the respondents

Table 4. The impacts of COVID-19 on horticulture farmers' awareness, behavior and attitude toward post-harvest losses, results expressed as percentage of the respondents ( $\mathrm{n}=300$ ).

\begin{tabular}{|c|c|c|c|c|c|c|c|c|c|c|c|c|c|c|}
\hline \multirow[t]{2}{*}{ \% Respondents } & \multirow[t]{2}{*}{ All } & \multicolumn{2}{|c|}{ Gender } & \multicolumn{4}{|c|}{ Age (years old) } & \multicolumn{4}{|c|}{ Members per household } & \multicolumn{3}{|c|}{ Education** } \\
\hline & & women & men & $18-30$ & $31-40$ & $41-60$ & $>61$ & 1 & 2 & 3 & $>4$ & Level 0 & Level 1 & Level 2 \\
\hline \multicolumn{15}{|l|}{ Reported Awareness } \\
\hline Yes & 8 & 18 & 9 & $10 *$ & $15^{*}$ & $18 *$ & $26^{*}$ & 0 & 2 & 5 & 3 & $0 *$ & $1 *$ & $4 *$ \\
\hline No & 14 & 18 & 11 & $12 *$ & $10 *$ & $21 *$ & $17 *$ & 0 & 9 & 5 & 4 & $2 *$ & $4 *$ & $13^{*}$ \\
\hline Not planned & 78 & 64 & 80 & $78 *$ & $75^{*}$ & $61 *$ & $57 *$ & 100 & 89 & 90 & 93 & $98 *$ & $95^{*}$ & $83^{*}$ \\
\hline \multicolumn{15}{|l|}{ Efforts to limit losses } \\
\hline Yes & 88 & 93 & 94 & $79 *$ & $80 *$ & $91 *$ & 100 & $90 *$ & $98^{*}$ & $100 *$ & $100 *$ & $82 *$ & $90 *$ & $100 *$ \\
\hline No & 10 & 4 & 4 & $12 *$ & $14 *$ & $5 *$ & 0 & $8^{*}$ & $1^{*}$ & $0 *$ & $0 *$ & $10^{*}$ & $6^{*}$ & $0^{*}$ \\
\hline No option & 2 & 3 & 2 & $9 *$ & $6^{*}$ & $4 *$ & 0 & $2^{*}$ & $1^{*}$ & $0 *$ & $0 *$ & $8 *$ & $4 *$ & $0 *$ \\
\hline \multicolumn{15}{|c|}{ Changes in market accessibility } \\
\hline Yes & 100 & $80^{*}$ & $99 *$ & $95^{*}$ & $99 *$ & $98 *$ & $97^{*}$ & $99 *$ & $98^{*}$ & $94 *$ & $100^{*}$ & $100 *$ & $97 *$ & $99 *$ \\
\hline No & 0 & $20 *$ & $1 *$ & $5^{*}$ & $1^{*}$ & $2 *$ & $3^{*}$ & $1 *$ & $2 *$ & $6^{*}$ & $0 *$ & $0^{*}$ & $3 *$ & $1 *$ \\
\hline \multicolumn{15}{|c|}{$\begin{array}{l}\text { Reported intentions to minimize } \\
\text { produce sale leftover at the market }\end{array}$} \\
\hline Yes & 100 & $99 *$ & $98 *$ & $98 *$ & $96^{*}$ & $95^{*}$ & $99 *$ & $97 *$ & $98^{*}$ & $99 *$ & $100 *$ & $93^{*}$ & $96^{*}$ & $100 *$ \\
\hline No & 0 & $1 *$ & $2 *$ & $2 *$ & $4^{*}$ & $4^{*}$ & $1 *$ & $2^{*}$ & $2^{*}$ & $0 *$ & $0 *$ & $4 *$ & $3 *$ & $0^{*}$ \\
\hline Do not think about the issue & 0 & $0^{*}$ & $0^{*}$ & $0^{*}$ & $0 *$ & $1 *$ & $0^{*}$ & $1 *$ & $0^{*}$ & $1 *$ & $0^{*}$ & $3 *$ & $1 *$ & $0^{*}$ \\
\hline \multicolumn{15}{|c|}{$\begin{array}{l}\text { Management practices of unsold produce } \\
\text { at the close of markets }\end{array}$} \\
\hline Sudden reduction of prices & 82 & $70 *$ & $88^{*}$ & $77 *$ & $91 *$ & $80 *$ & $91 *$ & $86^{*}$ & $82 *$ & $75^{*}$ & $86^{*}$ & $45^{*}$ & $39 *$ & $70^{*}$ \\
\hline Take the produce back home & 5 & $10^{*}$ & $1 *$ & $2 *$ & $0^{*}$ & $6^{*}$ & $1 *$ & $2^{*}$ & $8^{*}$ & $10 *$ & $5 *$ & $40^{*}$ & $36^{*}$ & $0 *$ \\
\hline Processing (Value addition) & 13 & $20 *$ & $11^{*}$ & $21 *$ & 9* & $14 *$ & $8^{*}$ & $12 *$ & $10^{*}$ & $15^{*}$ & $9 *$ & $15^{*}$ & $25^{*}$ & $30 *$ \\
\hline
\end{tabular}

$* \mathrm{P}<0.05$ : for each Chi-square test, the percentage shown represent column proportions. $* *$ Level $0=$ no formal education, Level $1=$ Primary \& Education School, Level $2=$ tertiary $(a$ holder of at least a certificate up to a $\mathrm{PhD}$ ) 
To the question "Does the changes in market accessibility affected quantities of produce sold per day, during COVID-19 crisis," $100 \%$ claimed positive and significant associations were found between the changing market accessibility and gender, age, number of member per household and education (Chi-square test, $\mathrm{P}<0.05)$ (Table 4).

Summarily, this study showed that the COVID-19 lockdown had a positive influence on producers' behaviors toward produce loss prevention. Fanelli \& Di Florio (2016) observed a similar trend on the producer's behavior during times of crisis. The findings emphasized the need to implement government incentive strategies such as information campaigns. This can assist the horticultural farmers to improve on their post-harvest handling techniques, adopt homemade solutions in minimizing crop loses and embracing of the modern technologies in farming e.g e-commerce.

\section{Marketing behaviors and attitudes of horticultural farmers during the lockdown}

Alignment of production levels with market availability is considered as key to reducing produce loss (Thornton \& Nel, 2007). In assessing farmer attitudes toward horticulture production levels, the farmers were asked about their production behavior and their markets availability. Figure 1 shows reported horticultural produce marketing behaviors (selling at below normal prices and selecting markets places). To the question of the horticulture produce selling prices and choice of markets, $70 \%$ confirmed to sell at below normal prices and $55 \%$ were had no choice of the market place (Figure 1). Only 5\% confirmed to sell below normal prices and select markets.

Extra-ordinary behavior alteration was important during the COVID-19 lockdown, the farmers will sell at below normal prices and had no choices on the markets. During the COVID19 lockdown, people are urged to minimize movements and stay home. This restrictions could have caused the markets to be partially accessible and customers to reduce their consumption pattern of the horticultural crops so low demand. The farmers would then sell at reduced prices in order to increase sales. The change of behavior was probably caused by a loss of income of the people and restricted market accessibility impairing the customers' availability. Agriculture is essential in ensuring food security in Zimbabwe (Zimbabwe Department of Agriculture and Extension Services, 2013). This could explain why farmers were not submitted to the lockdown measures in Zimbabwe though adhering to the social distancing requirements and restricted marketing periods (0600-0800hrs). Based on previous study on the producers and consumers' behaviors, prevention of produce loss during the COVID-19 lockdown was more associated with direct personal benefits than to the environmental concern (van Geffen et al., 2020).

\section{Quantity of spoiled horticultural produce during the COVID-19 lockdown}

Farmers were asked to estimate the total percentage of crop produce loss by categories expressed as the percentage of unsold crop produce (Figure 2). These results are only estimate hence should be interpreted carefully but still remain useful understanding the way horticultural farmers perceive the extent of produce loss, especially during the COVID-19 lockdown. According to the farmers, tomatoes were the most perishable, followed by leaf vegetables and the least perishable were the sweet potatoes, butternuts and others crops (Figure 2).

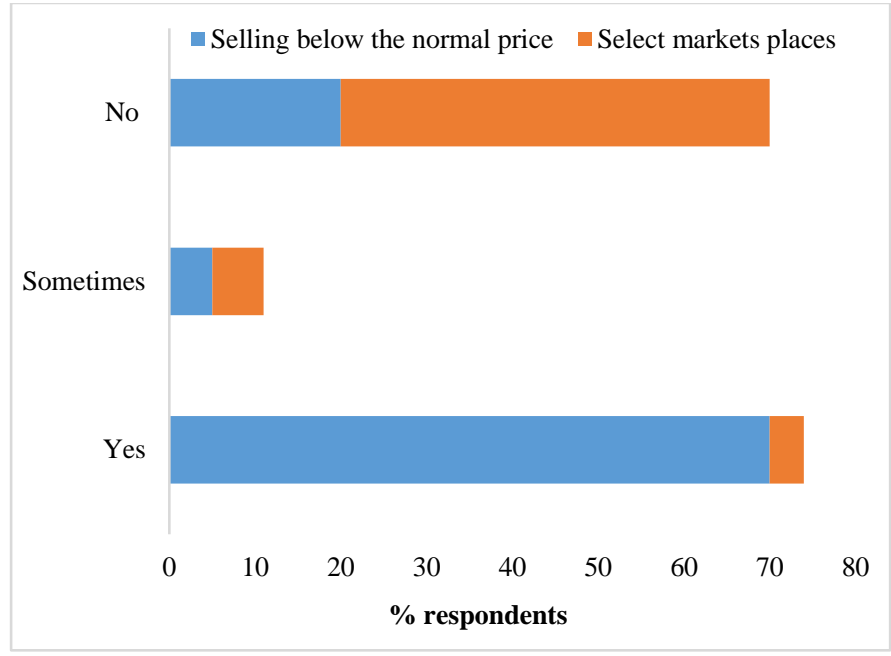

Figure 1. Summary of the horticultural produce sales during the lockdown, expressed as the percentage of respondents $(n=300)$.

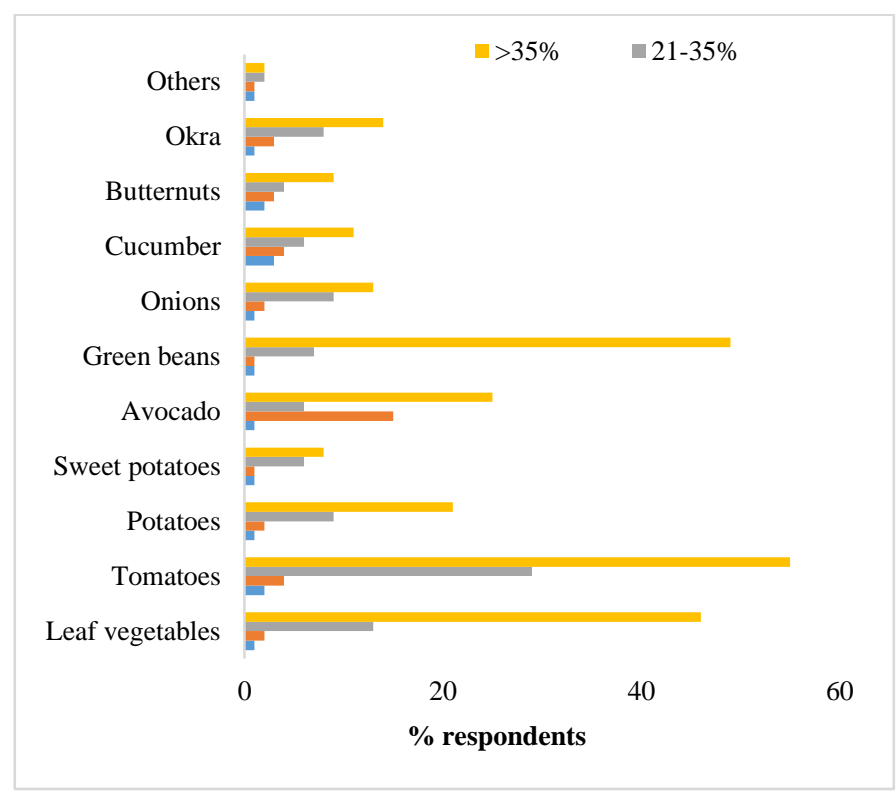

Figure 2. The proportion of spoiled crop produce during the COVID-19 lockdown, expressed as the percentage of respondents $(n=300)$.

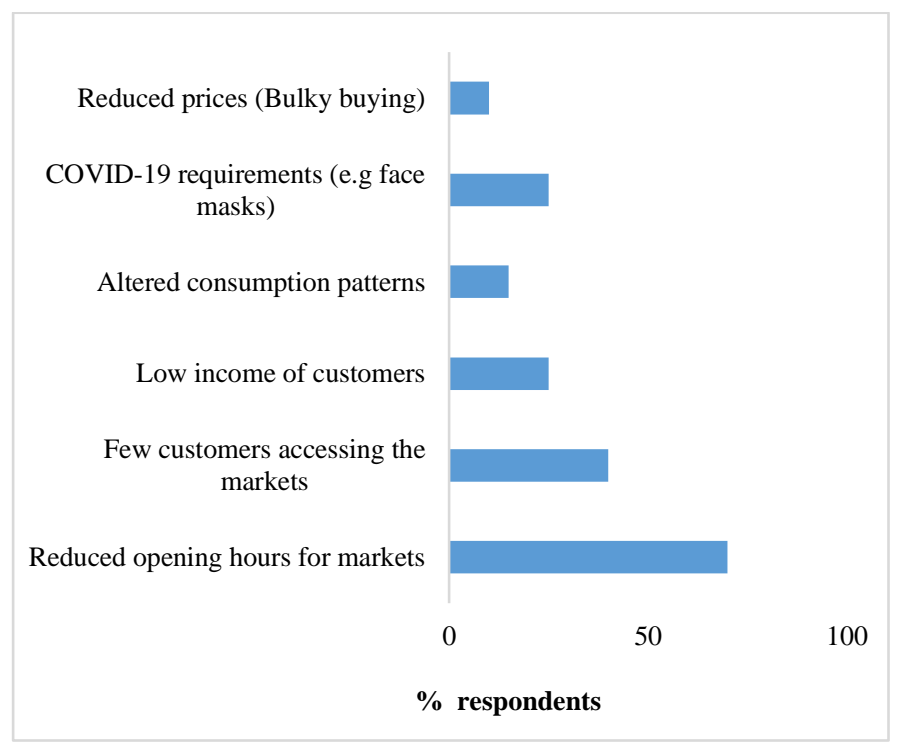

Figure 3. Possible reasons for the reduced sales of horticultural produce during the lockdown, values in percentage $(n=300)$. 
Table 5. The percentage of the respondent of horticulture farmers' intentional behavior towards minimizing produce loss $(\mathrm{n}=300)$

\begin{tabular}{|c|c|c|c|c|c|c|c|c|c|c|c|c|c|c|}
\hline \multirow{2}{*}{$\%$ Respondents } & \multirow{2}{*}{ All } & \multicolumn{2}{|c|}{ Gender } & \multicolumn{4}{|c|}{ Age (years old) } & \multicolumn{4}{|c|}{ Members per household } & \multicolumn{3}{|c|}{ Education** } \\
\hline & & Women & Men & $18-30$ & $31-40$ & $41-60$ & $>61$ & 1 & 2 & 3 & $>4$ & Level 0 & Level 1 & Level 2 \\
\hline \multicolumn{15}{|l|}{$\begin{array}{l}\text { Future intentions to reduce } \\
\text { produce loss }\end{array}$} \\
\hline Certain & 89 & 80 & 90 & $81^{*}$ & $75^{*}$ & $78^{*}$ & $53^{*}$ & 88 & 80 & 90 & 93 & $76^{*}$ & $95^{*}$ & $92 *$ \\
\hline Probable & 6 & 10 & 5 & $12 *$ & $10^{*}$ & $20 *$ & $10^{*}$ & 6 & 14 & 4 & 4 & $16^{*}$ & $3 *$ & $3 *$ \\
\hline Already do whatever I can & 5 & 5 & 4 & $6^{*}$ & $15^{*}$ & $2 *$ & $33^{*}$ & 3 & 6 & 4 & 2 & $6^{*}$ & $2 *$ & $5^{*}$ \\
\hline No & 0 & 5 & 1 & 1 & 0 & 0 & 4 & 3 & 0 & 2 & 1 & $2^{*}$ & $0 *$ & $0 *$ \\
\hline \multicolumn{15}{|l|}{$\begin{array}{l}\text { Conditions needed to reduce } \\
\text { produce losses in future }\end{array}$} \\
\hline Do not think about it & 8 & $3 *$ & $4^{*}$ & $9 *$ & $8^{*}$ & $1 *$ & $0^{*}$ & $8 *$ & $1 *$ & $0^{*}$ & $0^{*}$ & $10^{*}$ & $6^{*}$ & $0 *$ \\
\hline $\begin{array}{l}\text { Information on negative impacts of } \\
\text { horticultural losses on the income } \\
\text { generation }\end{array}$ & 97 & $88 *$ & $74^{*}$ & $89 *$ & $66^{*}$ & $84 *$ & $90 *$ & $92 *$ & $81^{*}$ & $90^{*}$ & $90 *$ & $78^{*}$ & $84 *$ & $100 *$ \\
\hline \multicolumn{15}{|l|}{$\begin{array}{l}\text { Information on negative impacts of } \\
\text { COVID-19 lockdown on } \\
\text { horticultural markets }\end{array}$} \\
\hline Inaccessible & 30 & $20 *$ & $40^{*}$ & $35^{*}$ & $29 *$ & $23 *$ & $7 *$ & $19 *$ & $38^{*}$ & $14^{*}$ & $30 *$ & $35^{*}$ & $27 *$ & $32 *$ \\
\hline Short opening hours & 40 & $30 *$ & $2 *$ & $22 *$ & $5^{*}$ & $2 *$ & $10^{*}$ & $9 *$ & $12 *$ & $31^{*}$ & $25^{*}$ & $41^{*}$ & $13 *$ & $28 *$ \\
\hline Low selling prices & 25 & $45^{*}$ & $50 *$ & $40 *$ & $60^{*}$ & $70 *$ & $70 *$ & $45^{*}$ & $32 *$ & $26^{*}$ & $35^{*}$ & $15^{*}$ & $44 *$ & $31 *$ \\
\hline Others & 5 & $5^{*}$ & $8^{*}$ & $3^{*}$ & $6^{*}$ & $5 *$ & $13^{*}$ & $27 *$ & $18^{*}$ & $29^{*}$ & $10 *$ & $9 *$ & $16^{*}$ & $9 *$ \\
\hline
\end{tabular}

*P<0.05: for each Chi-square test, the percentage shown represent column proportions. ** Level $0=$ no formal education, Level $1=$ Primary \& Education School, Level $2=$ tertiary (a holder of at least a certificate up to a PhD). 
The farmers were asked to qualitative rate the crop type that easily lose quality during the COVID-19 lockdown. About $58 \%$ of the farmers indicated that they could lose $>35 \%$ of tomato produce while crops like sweet potatoes, butternuts and others were reported to spoil slowly compared to the tomatoes and leaf vegetables (Figure 2).

Concerning the reasons of reduced produce sales during COVID-19 lockdown, 70\% respondents reported the reduced marketing hours (opened from 0600-0800hrs), $40 \%$ few customers accessing the markets, 25\% low income of customers and COVID-19 prevention requirements (e.g. wearing of face masks), $15 \%$ altered consumption levels and only $10 \%$ to reduced prices (bulky buying) (Figure 3).

\section{Information needs and willingness to reduce losses of unsold produce}

Table 5 shows farmers' future intention to minimize produce losses. Most (89\%) of the farmers indicated to be willing to modify their production levels toward reducing produce losses. Only 6\% showed that they will probably alter their behavior. Somehow, the data indicated a perceived responsibility as part of the solution to averting produce loss (van Geffen et al., 2020). Such behavioral changes can form the basis for implementing produce loss prevention and minimizing measures. This was related to the absence of effective post-harvest handling facilities at the farm level. A $5 \%$ of the farmers stated that they are already doing something to minimize the produce loss. Significantly $(\mathrm{P}<0.05)$ positive associations were found between future intention to produce loss minimization and age and education (Table 5).

Farmers were also asked about the requirements to minimize future post-harvest losses (Table 5). Surprisingly, $8 \%$ of the farmers did not worry about the need to minimize losses of the unsold produce. Limited information can partly explain the high losses in post-harvest of horticultural crops in Zimbabwe. The farmers (97\%) wanted more information about the negative impacts of COVID-19 lockdown on the income generation. On the impacts of COVID-19 lockdown on horticultural markets, $30 \%$ indicated market inaccessibility, $40 \%$ short opening hours, $25 \%$ reduced selling price and $5 \%$ showed others (Table 5). The requirements for minimizing produce losses and the impacts of COVID-19 lockdown on horticultural markets were significantly associated with gender, age, education and number members per household (Table 5).

The results are in agreement with those of Thornton \& Nel (2007), who indicated the need of more information and advices in minimizing the post-harvest crop losses in horticulture. Information sharing is one of the common approaches used to promote the strategies to minimize produce losses. The information dissemination can increase postharvest loss awareness in horticulture, which in turn can promote environmental behavior change (van Geffen et al., 2020). The information tools has to address the specific knowledge gaps that drive to prolonged shelf-life of horticultural crops.

Similarly, Zimbabwe Department of Agriculture and Extension Services (2013) observed that the information campaigns alone may not be efficient in changing the horticultural farmers' behavioral toward the post-harvest losses. They are other recommendations are associate with non-informational intervention such as input support like the command agriculture in Zimbabwe, policy implementation and monetary incentives.
The findings of this study raise the question whether the farmers' behavioral changes will outlast the COVID-19 lockdown period. Besides, the controlling and discovering of specific vaccines or treatments for the disease, COVID-19 outbreak provides opportunities to try new technologies in achieving efficient marketing and reducing the post-harvest handling loss during and even beyond this crisis. United Nations (2009) noted the need for a lasting change of behaviors toward horticultural marketing after an economic crisis.

\section{Conclusions}

The farmers have developed positive attitudes toward the controlling of the post-harvest loss; during the first month of the lockdown. The results suggested that the need to minimize post-harvest losses of horticultural crops was driven by the socio-economical context of the COVID-19 crisis (i.e., market availability, restricted movements, loss of income). There were significantly $(\mathrm{P}<0.05)$ more cases $(>35 \%)$ of produce sale leftovers at the markets and spoilage during than prior the COVID-19 lockdown. In order to maintain the positive COVID-19 driven behaviors toward minimizing post-harvest losses horticulture, education and communication campaigns must be intensified raising the awareness of poor post-harvest management consequences and benefits of increasing produce shelf-life at farm levels. Alignment of production levels with market availability interventions and application of modern technologies in horticultural marketing are necessary.

The study contributes to a better understanding of how a crisis situation can influence the marketing and raises awareness to post-harvest losses of horticultural crops. There was need to increase the market accessibility and lengthening of the opening hours of the farmer markets. It is recommended to qualitative studies as a follow-up to this work. The COVID19 pandemic can present numerous opportunities after the crisis and finding vaccines, making mid-and long-term improvements in reducing post-harvest losses in horticulture.

\section{References}

CDC (2020): Coronavirus (COVID-19). https://www.cdc.gov/ coronavirus/2019-ncov/index.html. Accessed 10 March 2020.

Fanelli, R. M., Di Florio, A. (2016): Domestic food waste, gap in times of crisis. Italian Review of Agricultural Economics, 71(2), 111-125.

Qi, D., Roe, B. E. (2016): Household food waste: Multivariate regression and principal components analyses of awareness and attitudes among US consumers. PLoS ONE. https://doi.org/10.1371/journ al.pone.01592 50.

Sassi, K., Capone, R., Abid, G., Debs, P., El Bilali, H., Daaloul, B. O. (2016): Food wastage by Tunisian households. International Journal AgroFor, 1(1), 172-181.

Thornton A. C., Nel E. (2007): The significance of urban and peri-urban agriculture in Peddie, in the Eastern Cape Province, South Africa. Journal of Development Studies. Volume. 37 No. 1. 13-23.

United Nations. (2009): International Market Access Information, Horticulture Sector, Geneva: UN.

Van Geffen, L., van Herpen, E., van Trijp, H. (2020): Household Food waste - How to avoid it? An integrative review. In E. Närvänen, N. Mesiranta, M. Mattila, \& A. 
Heikkinen (Eds.), Food Waste Management. Basingstoke: Palgrave Macmillan.

World Bank. (2008): World development report: Agriculture for development. Washington DC, USA.

World Health Organization (WHO) (2020): Coronavirus disease (COVID-19) Pandemic. https://www.who.int/ emergencies/diseaes/novel-coronavirus-2019. Accessed 10 April 2020.
Zimbabwe Department of Agriculture and Extension Services, Mutare District Annual Report (2013): Annual report 2013: Mutare District Agricultural Main Report. Mutare, Zimbabwe: Agritex.

Zimbabwe Horticultural Promotion Council (2013): Bountiful Zimbabwe. Harare: Zimbabwe Horticultural Promotion Council.

https://www.voanews.com>zimbabwe. Accessed 10 April 2020. 